\title{
A Study of the Teaching Reform of Practical Ability Cultivation in Formative Evaluation of Health Regulations
}

\author{
Tao Wu, Juan Song, Li Jiang, Shanshan Mei* \\ School of Health Services Management \\ Xi'an Medical University \\ Xi'an, Shaanxi Province, 710021
}

\begin{abstract}
At present, health law talents cultivated in colleges and universities have generally insufficient practical ability, so it is urgent to improve the cultivation of such talents' practical ability. This paper first clarifies the guiding ideology of the cultivation plan, and then analyzes the cultivation of teachers' practical ability, communication with employers and the broad understanding of practical ability cultivation, and finally, it elaborates on the viewpoints on the cultivation of health law professionals' practical ability.
\end{abstract}

\section{Keywords—Health Law; Practical Ability; Teaching Reform}

\section{INTRODUCTION}

The birth of health law is a natural response to the development of the bio-psycho-social medical model. While paying attention to the living conditions of human beings, the latter even pays more attention to the social living conditions of human beings. It can be seen that the health law itself, which is created for the purpose of protecting the two living conditions of human beings, is itself a tool. The ability of the specific people who use this tool, i.e., the health law talents, to use this tool directly influences and determines the effectiveness of this tool.

In 2011, the "Central Political and Legal Committee of the Ministry of Education on Several Opinions on the Implementation of the Excellent Legal Personnel Training Program" (J.G. [2011] No. 10) pointed out there are such problems in the legal education in China: "The training mode is relatively simple, the students' practical ability is not strong, and the application-type and compound legal professionals are insufficiently trained." Then, as a new cross-cutting discipline that has only been developed for more than a decade, the health law has fully adapted and met the objective social needs of the professional talents it cultivates. The actual answer is largely negative. [1-4].

There are many reasons for this, such as the lack of attention and inactivity of students' attitudes, [5] old subject assessment mechanism [6], inherent thinking of traditional training mode [7], etc. For these reasons, many academic colleagues have carried out a large number of fruitful and practical activities to improve and reverse this situation, such as the application of case teaching methods, the exploration of new teaching models, the reevaluation of the subject evaluation

Project Information: Xi'an Medical University's Curriculum Evaluation Innovation Action Plan Teaching Reform Research Project: Health Regulations Curriculum Evaluation Innovation Action Implementation Plan, No.121619022 system, and so on. Undoubtedly, these efforts and attempts are very helpful to enhance the practical ability to cultivate health law talents and promote the development and progress of the discipline. In view of this, the author also hopes to express his personal opinions and opinions on this subject based on his shallow professional experience and combined with the feelings of the past. This is also a preliminary exploration.

\section{The Guiding IDEOlogy for Cultivating Practical ABILITY SHOULD BE CLEAR}

There is a difference in the purpose and talent training objectives of the health law majors offered by each university. For example, some of them focus on cultivating legal practitioners, that is, to deliver professional talents to courts and lawyers; some directly target the service. For example, the school where the author works is directly positioned to cultivate practical talents for serving the primary and secondary medical institutions in the central and western regions of China. Then the talent training mode of such institutions must be closer to the grassroots and practical than the former, and the image is more "local".

The four-year education time of the undergraduate course is limited, so it is also a matter of cultivating practical ability as the main task, and the method of achieving the purpose is definitely different. This is most evident in the curriculum, the allocation of class hours, internships, and directional guidance for graduation thesis. For example, the institutions that focus on cultivating legal and practical talents will inevitably take into account the judicial examinations and civil service examinations involved in industry access. The institutions that use the service-based level will definitely reflect the emphasis on the development of students' communication skills in the training plan.

Correspondingly, after the orientation of the teaching unit is clear, students who are also suitable for training will adjust and determine their own learning arrangements and career plans to make the most of the existing resources. Of course, while clarifying the direction of faculty training, it does not exclude and resist the students' planning of their own development according to their own interests. This requires both teachers and students to understand each other and study the ways of learning and progress that suit everyone. 


\section{Cultivation of Practical Ability of Health LAw EDUCATORS AND THEIR TIMELINESS}

"Health Law is a research law on health law, and it is a departmental law to study the social phenomenon of health law and its development law. ${ }^{[9]}$, The research and practice objects of this discipline are developmental changes. Therefore, it is necessary to first understand and master this "law of development" at the beginning of the establishment of the important goal of the talent cultivation plan with practical ability. What needs to be specially mentioned is that the emphasis here is on the teaching staff, that is, the knowledge structure and practical ability of the teachers of health law are advancing with the times.

Before guiding and helping students develop the practical ability, teachers should have a comprehensive and objective understanding and mastery of the objects of practice, and then update and adjust their knowledge structure according to actual needs. Before the teacher teaches the students, they first have the ability to face and solve problems, so that it is possible to guide and train the students to complete the ability development goals. Otherwise, simple classroom design and simulation exercises are unable to achieve the practical skills envisioned in the teaching objectives. ${ }^{[10]}$ In this way, it is necessary to supervise and urge teachers to carry out the practice from the system construction. For example, the teacher is required to conduct regular research visits to the legal service departments or the grassroots service organizations targeted by the teaching plan.

Only the combination of the cultivation of the practical ability of health law teachers and the student development plan can promote the common progress of teaching and learning.

\section{IV. “The Sense Of Site” Is NeEded in the Cultivation of PRACTICAL ABILITY}

The practice of ability development is inseparable from the experience of the practical environment, which includes real simulation of two environments. In contrast to the latter, the most typical implementation is to simulate the practice training of the court. This paper mainly describes the former.

The real practice training environment refers not only to leading students to the court to observe and observe the process of the trial, to participate in specific law enforcement processes, or to practice the students in the internship unit during the internship. The real environment mentioned here also includes the specific experience of a certain event party who comes to the middle of the student to tell and explain himself. Through the re-enactment of the witnesses, the incident will certainly be greater than the case analysis class conducted by the teacher, so it can be seen as a recurrence of real events.

For example, the author's school is based on the service of the grassroots, and the grassroots health supervision and law enforcement departments are in urgent need of health law talents. Our school may be able to hire law enforcement officers from the institution to conduct lectures and practical course training for health law students and students on their own real experience in supervising law enforcement. In addition to the advantages of true restoration, the practical training of this form has the greatest advantage that the witnesses, students and teachers can jointly experience, analyze and evaluate the occurrence, development and outcome of the event. Throughout the process, students can analyze the incidents under the guidance of the teachers, and the parties can evaluate the incidents according to their personal experiences, and provide feedback on the opinions and suggestions of teachers and students.

Through this form of training, students can understand and grasp the ins and outs of events to enhance their understanding of practical work. Teachers can analyze the events by participating in the understanding of real cases and using their academic advantages. At the same time, they can deeply discuss some specific details of the research events with the parties, and finally, enable the parties to have a deeper understanding of the events. In turn, teachers can improve teaching, and parties can improve their professional quality to better carry out their future work.

\section{CONSIDER the MEANing of Practical ABILITy FROM THE PERSPECTIVE OF EMPLOYERS}

The definition of practical ability can be different. For the legal practice department, it is more necessary to be proficient in the law and application; for medical institutions at all levels, it may be more focused on communication skills. Therefore, according to the different educational goals of each department, the specific needs of the health law talents should be fully considered. Of course, the ability to practice, the ability to communicate, the ability to negotiate, the ability to negotiate, the ability to investigate, the ability to investigate, and the ability to adapt. There is no obvious distinction between primary and secondary abilities. However, in the actual curriculum setting and class schedule, the weight distribution and grasp of each course should be worthy of scrutiny.

In the process of this trade-off and trade-off, the opinions and suggestions of the service target units of the discipline should be regarded as an important consideration. Because the teaching purpose of the teaching unit is achieved, the employment unit of the talent has a very important voice. However, in the past, the degree of integration between schools and employers was not very close, and sometimes even out of touch. Now, through the joint development of practical capacity development programs, it is expected that barriers between teaching and employment will be opened.

Through various forms of communication, such as symposiums, the relevant person in charge of the employer and the graduate representatives who have been employed can be invited to talk with the teachers and students. Employers can clearly state what specific requirements and expectations they have for graduates. The alumni who have already worked can analyze their own needs after graduation, and the first is the feedback on the previous teaching effect, and the second is to pave the way for their continued education; for teachers and students, attending this event is very helpful in clarifying future teaching and learning goals. 
combine the characteristics of their respective research and teaching institutions and their own interests, and conduct research and teaching in an all-round and multi-angle attitude. Moreover, the exchanges and interactions within the disciplines and interdisciplinary fields should be strengthened as much as possible, in order to achieve the goal of mutual learning and common progress and to cultivate the health law talents with better practical ability to help each other and contribute to the development and growth of health law.

\section{REFERENCES}

[1] Li Haijun, Feng Yuzhi. Research on Teaching Reform of Health Medicine in Clinical Medicine from the Perspective of Professional Certification [J]. China Health Legal System, 2017, 25 (03): 33-36.

[2] Zhou Huilei. On the Teaching Reform of Medical Professional Health Law [J]. Journal of Henan Institute of Education (Philosophy and Social Sciences Edition), 2018, 37 (03): 122-125.

[3] Zhang Xuehui, Ren Caixia, Li Yueping, Lin Yulan. Application of Case-wide Pedagogy at Health Law Courses [J]. Journal of Fujian Medical University (Social Science Edition), 2019, 20 (02): 49-53.

[4] Wang Na. Discussion on the Teaching Mode of Health Law Course for Adult Higher Education in Medical Colleges [J]. Journal of Jiamusi Vocational College, 2018 (07): 166-167.

[5] Fang Wei, Ma Guofang, Chen Yu, Sun Ping. Exploration on the Teaching Reform of the Course of Health Law in Higher Medical Colleges [J]. Journal of Xinjiang Medical University, 2017, 40 (11): 1492-1495.

[6] Yang Guo Zehui. Analysis of Teaching Reform of Health Law[J]. Curriculum Education Research, 2017(25): 230-231.

[7] Zhai Yun, Liang Yanlong. Investigation and Analysis of the Status Quo of Medical Students' Health Law Courses in Higher Vocational Colleges - Taking Zhaoqing Medical College as an Example [J]. Health Vocational Education, 2019, 37 (01): 115-118.

[8] Wang Xuanlan. The Application and Reflection of the Simulated Court in the Teaching of Health Law [J]. Inner Mongolia Education, 2019 (21): 39-40.

[9] Liao Chenge. Investigation and Countermeasures for Perfecting the Curriculum System of Medical Law Majors - Taking the Medical Law Major of Binzhou Medical College as an Example [J]. Medicine and Law, 2016, 8 (04): 30-32.

Judging from the development of health law in China for more than a decade, this discipline is still in the initial stage of development. Researchers and teachers involved in the development process of the discipline should, as far as possible,
[10] Zhan Huan, Liu Dahua. Practical Exploration of Participatory Teaching in the Reform of Health Law Teaching [J]. Asia Pacific Education, 2016 (06): 70-71. 